\title{
Field Measurements of Vibration on the Car Body-Suspended Equipment for High-Speed Rail Vehicles
}

\author{
Jinying Guo, Huailong Shi (D, Fansong Li, and Pingbo Wu \\ State Key Laboratory of Traction Power, Southwest Jiaotong University, Chengdu 610031, China \\ Correspondence should be addressed to Huailong Shi; shi@swjtu.edu.cn
}

Received 8 October 2019; Revised 13 May 2020; Accepted 21 May 2020; Published 25 June 2020

Academic Editor: Rui Moreira

Copyright (C) 2020 Jinying Guo et al. This is an open access article distributed under the Creative Commons Attribution License, which permits unrestricted use, distribution, and reproduction in any medium, provided the original work is properly cited.

\begin{abstract}
The vibrations in the flexible car bodies of the high-speed electric multiple units (EMUs) and their coupling effects with the bogies and other types of equipment vibrating have lead issues for railway operators and gained interest for researchers. Other than a numerical investigation, field measurements on the vibrating characteristics of the car body $(\mathrm{CB})$ and its suspended equipment (CBSE) for a high-speed railway vehicle were performed to elaborate the vibrating characteristics on the CB and its CBSE. In this long-term tracking test, the running stability of vehicle and wheel-rail interaction were also examined with the increase of operation distance (OD), a total of $2,400,000 \mathrm{~km}$. The test configuration and arrangements are introduced first, followed by the data analysis in time and frequency domains. It is seen that the wheelset conicity increases 0.008 per $10,000 \mathrm{~km}$, which increases approximately linearly with the OD from 0.10 to 0.40 . Two types of wheel treads, S1002CN and LMB10, have different ranges in conicity and reprofiling cycles. The lateral accelerations on CB in a downward-running case $(0.5 \mathrm{~g})$ are much greater than that in upward-running case $(0.2 \mathrm{~g})$ corresponding to the vehicle stability differences. The $15 \mathrm{~Hz}$ low-pass filtered acceleration on $\mathrm{CB}$ experiences a maximum of $0.10 \mathrm{~g}$ and an averaged amplitude around $0.05 \mathrm{~g}$, whereas the frequency spectrum has peaks of $0.01 \mathrm{~g}$ on $\mathrm{CB}$ and $0.1 \mathrm{~g}$ on CBSE. It states that an elastic suspension between the CBSE and the CB prevents the high-frequency vibration from the $\mathrm{CB}$.
\end{abstract}

\section{Introduction}

For the modern railway vehicles, the car body (CB) has lower structural stiffness and lower eigenfrequencies resulting from reducing the weight of $\mathrm{CB}$, which may get so low that the $\mathrm{CB}$ structural vibrations would be easily excited; thus the ride comfort would be deteriorated significantly. Moreover, the bogie hunting motion and the structural vibrations of the $\mathrm{CB}$ are observed at the same time in field measurements; that is, a resonance occurs; thereby the vibrations on the $\mathrm{CB}$ and ride comfort of the vehicle are worsening more $[1,2]$. It is shown that the car body flexibility enlarges the floor vibration and ride comfort index, which are sensitive to the track irregularity and the structural geometry of vehicle $[3,4]$. Additionally, functional in-cabin devices are essential for electric multiple units (EMUs), intercity trains, and metro rail vehicles, such as the transformer, converter, cooling unit, air compressor, braking unit, and waste collection unit. The majority are suspended directly from the $\mathrm{CB}$ chassis (referred to as the $\mathrm{CB}$ suspended equipment (CBSE) in the following text). Among them, some weigh in the order of tons, such as the transformer and converter. Some are subjected to vibrational excitations, such as cooling fans and mechanical switches on CBSEs. For vibration reduction purpose, elastic suspension elements are generally used to connect such in-cabin devices and equipment to the $\mathrm{CB}$ chassis. The $\mathrm{CB}$ and the CBSE configure a coupled vibrating system, and the suspension of equipment affects the coupling vibration a lot.

A general design principle of the suspension parameters of CBSE has been proposed in the previous works [5]. Both the rigid and elastic vibrations of the $\mathrm{CB}$ would be reduced if the CBSE could work as a dynamic vibration absorber (DVA). With a DVA, the natural vibration of the CB would be reduced significantly if the CBSE suspension parameters are reasonably optimized, which has been verified by 
numerical analyses and lab tests [5-8]. However, the restricted installation space, mass, and volume of the CBSE in engineer application make the vibration reduction effect less significant in the field tests. In other words, the CB modal vibration still arises in operation even if the CBSE is suspended with the optimized suspension parameters $[9,10]$. Then further study is still needed.

Experimental measurements are commonly employed to analyze the railway vehicle dynamics on track and validate the modelling accuracy. Andersson et al. [11] built a vehicle dynamics model which was validated through field tests on the Italian high-speed train X2000. Based on the measured acceleration on the bogie, Gasparetto et al. [12] examined the hunting stability of a high-speed train on track. Through a long-term measurement on the wheel profile wear, Gan et al. [13] and Wang et al. [14] conclude the evolution of profile wear on wheel with the vehicle operation distance (OD) and dynamics behaviour of vehicle. Then, optimization on the wheel reprofiling interval was furtherly proposed concerning the vehicle running stability. The aforementioned field measurements concern the general vehicle vibrating resulting from wheel wear, but there is a little work about the coupled vibration between the $\mathrm{CB}$ and CBSE. This investigation aims at understanding the evolution of CBSE through a long-term test on track and the vibration transmission among the primary and secondary suspensions, for the high-speed trains CRH380 running on the Beijing-Shanghai (BS) and Harbin-Dalian (HD) high-speed railways within several continuous wheel reprofiling cycles. Recorded data are used to statistically evaluate the vibration of CB and multiple types of CBSE by studying the mean value and maximum of acceleration data, transmission characteristics, and their evolution with the wheel wear.

In the following of this paper, Section 2 is about the configuration of the field measurement, including the dataacquisition system, sensors arrangement, and the monitored physical quantities and points. Section 3 states the vibration behaviour of the $\mathrm{CB}$ and several CBSE in the time domain with the increasing of $\mathrm{OD}$. The associated vibrations in frequency domain are evaluated in Section 4 to show the motion of modes of bodies. Section 5 concerns the coupling vibration between the $\mathrm{CB}$ and CBSE, especially the excitations bears on the CBSE. This experimental study on the car body-mounted equipment vibration and the dynamic behaviour of the tested high-speed trains is summarised and concluded in Section 6.

\section{Field Tests of the Wheel Wear and Vehicle Vibration}

The data-acquisition system is introduced first, followed by the measuring method for the wheel wear, running stability, and the vibration transmission character of the CSBE suspension. The placement of the CBSE on the CB as illustrated in Figure 1 is for a high-speed train with a maximum operation speed of $300 \mathrm{~km} / \mathrm{h}$. They weigh approximately $8 \mathrm{t}$ in total, almost the same weight of the aluminium alloy structure of the CB. Former work groups them into several categories by weight and the subjected excitation [15]. Among them, the traction transformer and converter weigh much more than the others; that is, their vibration is most likely to be strongly coupled with CB.

2.1. Data-Acquisition System. The on-board test devices include accelerometers, displacement sensors and signalacquisition system, computer-based control system, and power supply unit. The accelerations of the axle box of wheelset, bogie frame, and CB along translational directions would be recorded with various sampling rates in a general vibration test for a railway vehicle. The arrangement of accelerometers is depicted in Figure 2, which is for the $\mathrm{CRH} 380 \mathrm{~B}$ high-speed trains on the BS high-speed railway at $300 \mathrm{~km} / \mathrm{h}$. The BS rail line mainly consists of tangent and curved tracks with large radius. The curved tracks with radius greater than $7000 \mathrm{~m}$ account for more than $20 \%$ and tangent tracks dominate for almost $70 \%$. The sampling rates and responding ranges of sensors are listed in Table 1 . The tests started from 2013 to 2017 and were carried out on one bogie on the first trailer car and one motor bogie on the first motor car along the trainset.

2.2. Wheel Wear Monitoring. The dynamic behaviour of a railway vehicle straightforwardly depends on the wheel-rail interaction, in which the profile of wheel plays a major role; thus, the monitoring of the profile shape of a worn wheel is crucial to the evolution of the dynamic performance. Then, the evolution of wheel profile is in need for better analysis of the coupled vibration between the CB and CBSE as well as the hunting stability. In this test, the MiniProf was used to measure the wheel profile as depicted in Figure 3; then worn profiles were compared to the reprofiled or standard one to evaluate their wear amount and associated evaluation indices. The wheelset equivalent conicity is commonly used to assess the wheel-rail interaction condition $[16,17]$. It depends on the rolling radius difference and the lateral displacement of wheelset. $r_{\mathrm{L}}$ and $r_{\mathrm{R}}$ represent the rolling contact radii of the left and right wheels, respectively, while the lateral displacement of wheelset is represented by $y_{w}$; then the conicity is written as $\lambda=\left(r_{\mathrm{L}}-r_{\mathrm{R}}\right) /\left(2 y_{w}\right)$. UIC 519 [18] specifies a nominal equivalent conicity with a lateral wheelset displacement of $3 \mathrm{~mm}$.

2.3. Acceleration Monitoring. Accelerometers are pasted on the axle box of wheelset, the bogie frame, and the car body to calculate the vibration transmission character of the primary suspension and the air spring systems (secondary suspension). Similar to that, the accelerations of the CBSE and CB are also monitored to grasp the coupled vibration transmission characteristics of the CBSE suspension as depicted in Figure 2. Since the literature $[10,14,19]$ pays a great attention to the vibration transmission character of the primary suspension and secondary suspension, the present work will focus on the vibration transmission character of the CBSE suspension. A higher sampling rate was monitored on the wheelset and the bogie frame than that on the CB and 


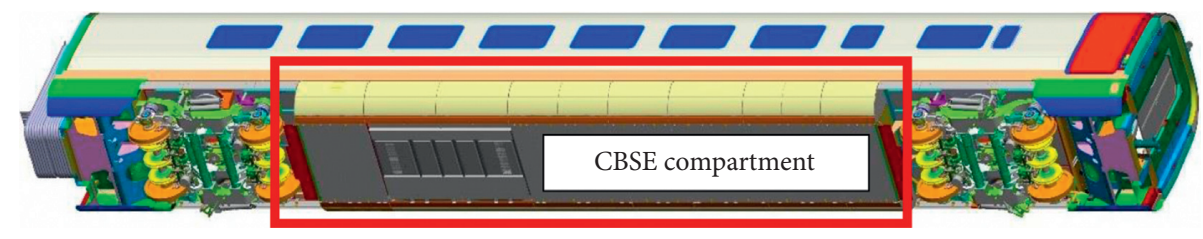

FIgure 1: A 3D drawing of the arrangement of CBSE on the CB.

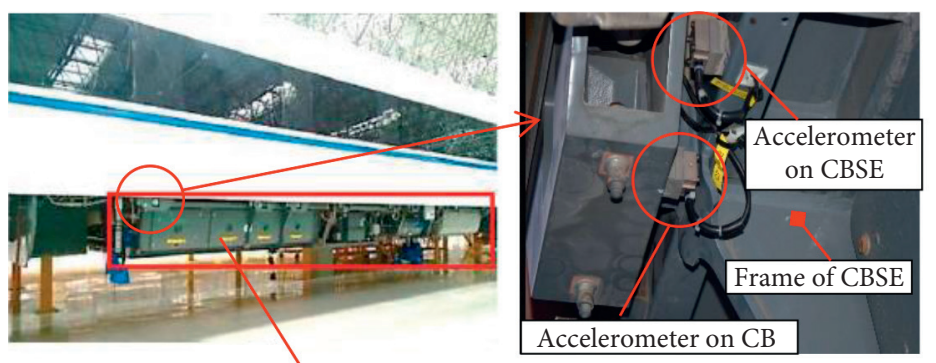

(a)

(b)

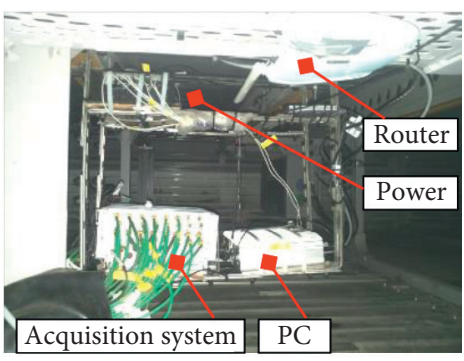

(c)

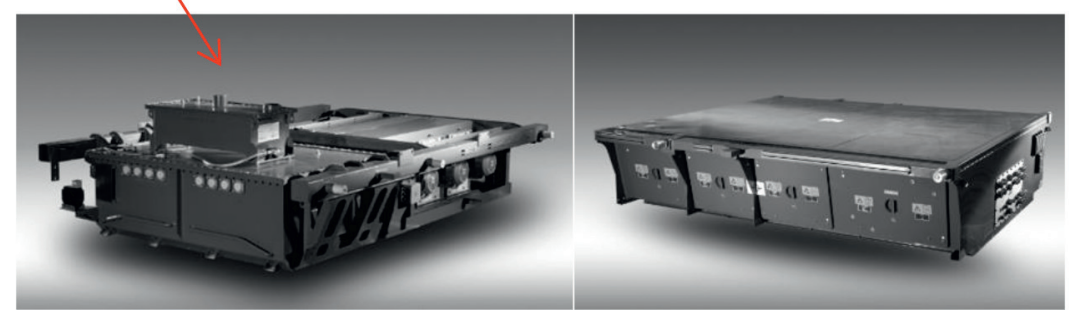

(d)

(e)

FIgURE 2: Field test for CRH380B: (a) CBSE under the car body chassis with cabin shield removed [10]; (b) accelerometers on CB and CBSE at the connection; (c) data-acquisition system on board; (d) CBSE traction transformer; (e) CBSE traction converter.

TABLE 1: Sampling rate and response range of sensors $\left(g=9.81 \mathrm{~m} / \mathrm{s}^{2}\right)$.

\begin{tabular}{lcc}
\hline Sensors & Response range & Sampling rate $(\mathrm{kHz})$ \\
\hline Accelerometers on CB and CBSE & $0-2 \mathrm{~g}$ & 1 \\
Accelerometers on bogie frame & $0-18 \mathrm{~g}$ & 2 \\
Accelerometers on wheelset & $100-500 \mathrm{~g}$ & 5 \\
GPS system & Train location and speed & 5 \\
Wheel profile measuring system & A general railway wheel width $140 \mathrm{~mm}$ & 0.1 \\
\hline
\end{tabular}

CBSE due to the high-frequency wheel/rail interacting forces. It is known that this high-frequency excitation can be isolated and damped through the two-stage suspensions.

2.4. Signal Processing and Data Analysis. The recorded data in one commute operation is divided into sets by train stations and running directions. Relating the vibration transmission character and dynamic performance with the increasing of OD helps to reveal how the dynamic behaviour changes with the operation conditions, such as the wheel wear, running directions, and atmospheric temperature.

The recorded acceleration data of the CB and CBSE are analyzed in both the time and frequency domains. Moreover, the mean value and maximum are obtained applying various filtering bandwidths of frequency. The averaged maximum acceleration is commonly used as an index of the vibrating level. For a specific history of signal, it is divided into several parts with an equivalent length of $5 \mathrm{~s}$; then the maximums associated with these parts would be averaged; thus the averaged maximum is obtained. In addition, the vehicle usually would behave differently when running upward and downward [10, 14]. When the train runs upward on the BS high-speed line, it is heading Beijing; otherwise, it is heading Shanghai.

\section{Vibration in Time Domain with the Increasing OD}

In this section, the vibration on the car body and the car body-suspended equipment, traction transformer, and converter which are heavy enough with respect to the car 


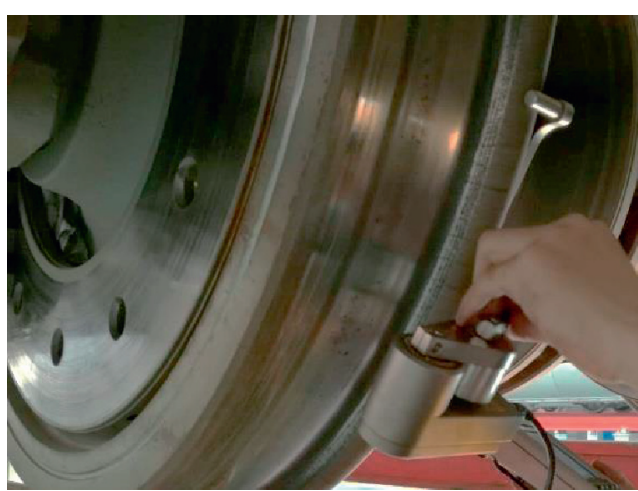

(a)

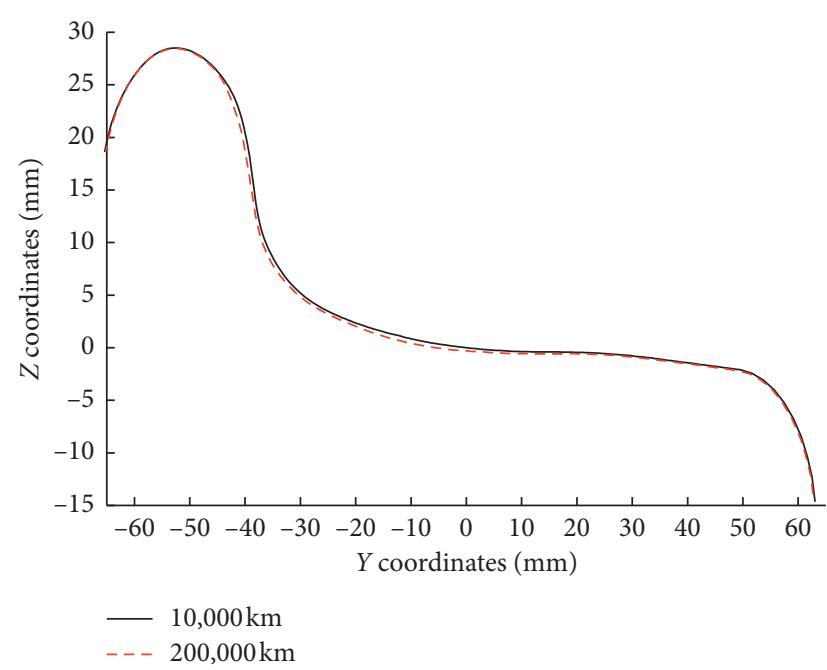

(b)

Figure 3: Wheel wear measurement: (a) wheel profile measurement instrument MiniProf; (b) measured wheel tread profiles.

body mass are examined by evaluating the amplitude of acceleration and its evolution with the OD of vehicle.

\subsection{Equivalent Conicity of Wheelset and Vehicle Stability.} Figure 4 depicts the equivalent conicity of wheelset with the increasing of the OD of vehicle. There are two rows of text for the $x$-axis; they are, respectively, the total running distance of the vehicle and the running distance after the wheel was reprofiled. The conicity of four wheelsets of one specific car or trainset is plotted as hollow circles and their corresponding averaged value is marked as a red solid circle. One can tell that the conicity increases approximately linearly from 0.10 to 0.40 with an averaged running distance of $400,000 \mathrm{~km}$. After the wheel reprofiling, the conicity of wheelset returns to its initial value. In the total OD of $2,400,000 \mathrm{~km}$, the test trainset was operated on different types of high-speed railway with an often used speed of $200 \sim 300 \mathrm{~km} / \mathrm{h}$, and two types of tread profile were used on this trainset, while a statistical analysis shows that the conicity increases about 0.008 per $10,000 \mathrm{~km}$ of OD. Correspondingly, the vehicle stability and the lateral vibration on the bogie deteriorate with the increasing of the wheelset conicity. Additionally, it is found that the wheel treads S1002CN and LMB10 have different ranges of conicity and reprofiling cycles regarding the vehicle OD. A further study states that both the operation conditions of the trainset and climate conditions influence the wheel wear, and different wear amount and worn area on tread or even on flange can be noticed which has been presented by Li et al. [20] in an international conference concerning contact mechanics.

It is known that the wheelset hunting motion of vehicle is a self-excited motion, in which the forward running energy from the traction power system is converted to the vehicle's lateral vibration through the wheelset/rail interaction [21]. The equivalent conicity of wheelset on rail directly determines the vibrating characteristics and amplitudes on the car body and bogie frame. Three generally used simplified lateral hunting dynamics intended vehicle models are illustrated in Figure 5, including a free wheelset model, a rigid-steering bogie model which concerns the wheelset which is rigidly connected to the bogie frame, and a flexible-steering bogie model with primary suspension between the wheelset and bogie frame. The lateral and yaw motions are the at least two degrees of freedom needed to be considered for each body in this simplified model, which are presented by symbols $y$ and $\psi$ followed by subscripts $w$ and $b$ which refer to the wheelset and bogie frame, respectively. The lateral half distance between the contact points on left and right wheels is noted as $b, L_{b}$ refers to the half wheelbase, $w_{p}$ is the half span of primary suspension, and running speed of vehicle is noted as $v$.

Considering a simple wheel/rail creepage and creep forces and creepage relationship, the differential equations of motion of the free wheelset can be written as

$$
\left\{\begin{array}{l}
m_{w} \ddot{y}_{w}=-2 f\left(\frac{\dot{y}_{w}}{v}-\psi_{w}\right), \\
I_{w z} \ddot{\psi}_{w}=-2 b f\left(\frac{\lambda}{r_{0}} y_{w}+\frac{b}{v} \dot{\psi}_{w}\right),
\end{array}\right.
$$

in which $r_{0}$ represents the nominal wheel radius and $f$ is Kalker creep coefficients which assume that the longitudinal and lateral coefficients are the same. For a free wheelset, its wavelength of hunting motion can be deduced from the Jacobian matrix of the differential equations as

$$
L_{w}=2 \pi \sqrt{\frac{b r}{\lambda_{e}}}
$$

in which $b$ represents the half distance between contact points on right and left wheel and is approximately $1500 \mathrm{~m}$ in case of a standard track gauge $1435 \mathrm{~mm}$ and $\lambda_{e}$ represents the equivalent conicity of wheelset resulting from the matching of the wheel profile and the rail profile. 


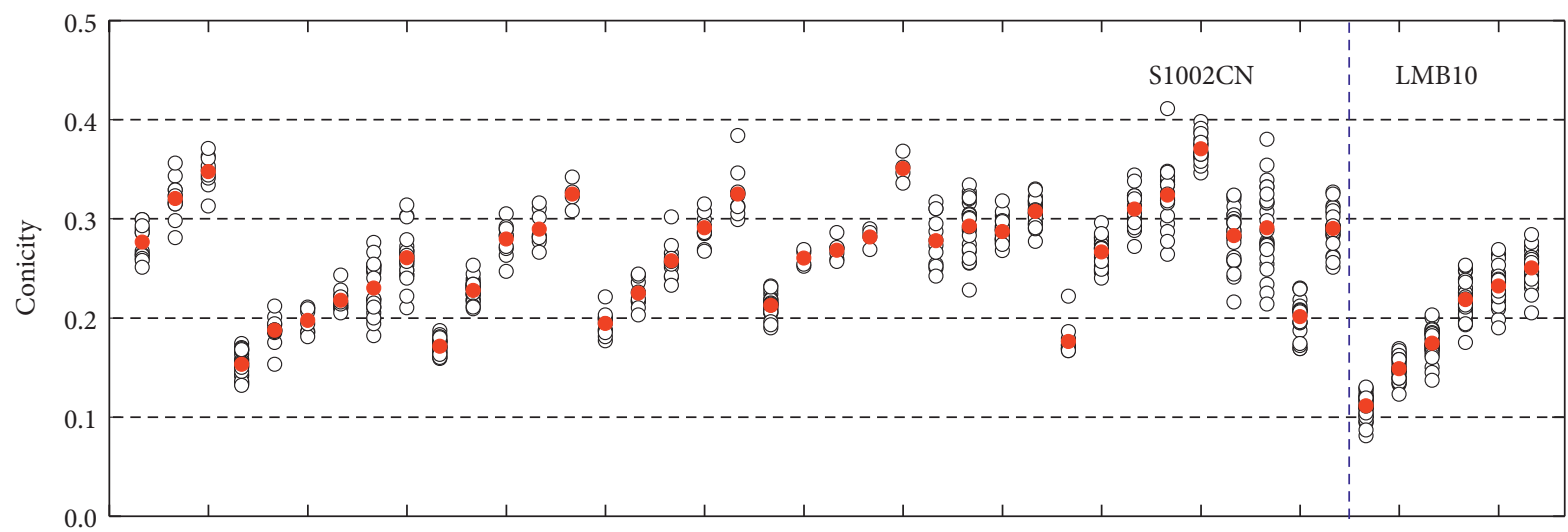

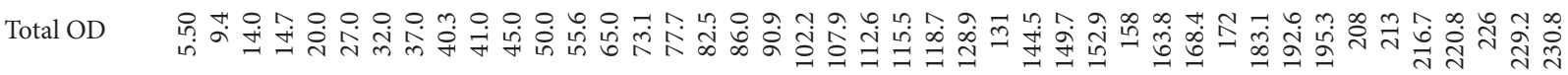
Reprofile OD 苛 Operation distance / $\left(1 \times 10^{4} \mathrm{~km}\right)$

- Conicity of wheelset

- Averaged conicity

FIGURE 4: Equivalent conicity of wheelset with the increasing of OD of the tested trainset.

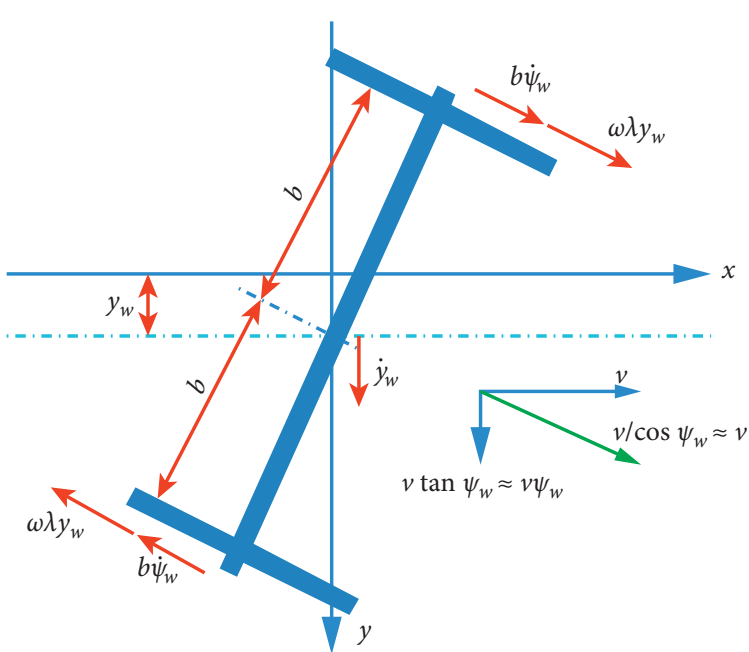

(a)

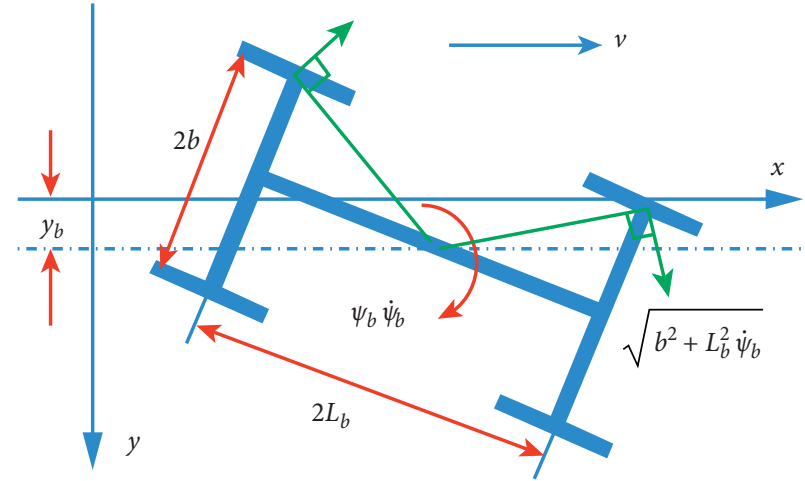

(b)

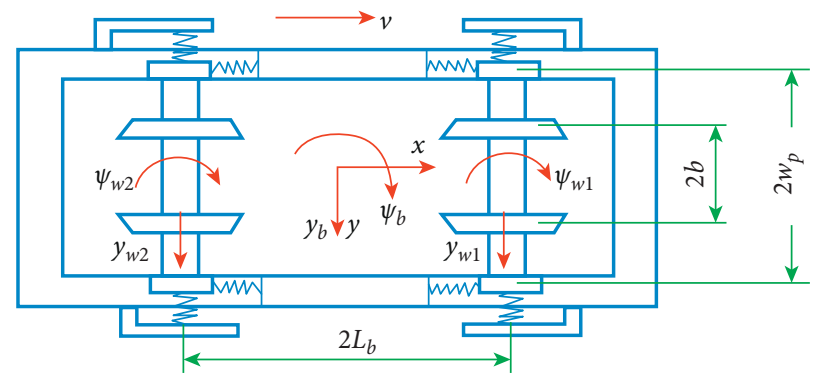

(c)

FIgURE 5: Simplified vehicle dynamics model for hunting study: (a) a free wheelset; (b) rigid-steering bogie; (c) flexible-steering bogie without secondary suspension. 
Similar to the differential equations of motion for the free wheelset model, the rigid-steering bogie model has only two degrees of freedom and its governing equations concern the wheelbase effect. Furtherly, the wavelength can be obtained by numerically solving the differential equations of a flexible-steering bogie. For a rigid steering case, the hunting wavelength is written as

$$
L_{b r}=2 \pi \sqrt{\frac{b r}{\lambda_{e}}\left(1+\frac{L_{b}^{2}}{b^{2}}\right)}=L_{w} \sqrt{1+\frac{L_{b}^{2}}{b^{2}}}
$$

in which $L_{b}$ represents the half distance of bogie wheelbase, for example, $1.25 \mathrm{~m}$.

For a flexible-steering bogie, its hunting wavelength is presented by

$$
L_{b s}=L_{w} \sqrt{1+\frac{L_{b}^{2}}{b^{2}}(1-\delta)},
$$

in which

$$
\left\{\begin{array}{l}
\delta=\frac{(1-\sigma Z)}{\left(1+Z^{2}\right)} \\
\sigma=(2 p-3) \beta^{2} \\
Z=\beta K^{p}
\end{array}\right.
$$

where $\beta=b / L_{b}, p=1+\left(k_{p \psi} /\left(k_{p \psi}+k_{p y} L_{b}^{2}\right)\right), K=\left(L_{w} / 2 \pi\right.$ $\left.f b^{2}\right) \cdot\left(k_{p \psi} k_{p y} L_{b}^{2} /\left(k_{p \psi}+k_{p y} L_{b}^{2}\right)\right), k_{p \psi}$ is the yaw stiffness of the wheelset, $k_{p y}$ is the lateral steering stiffness of the wheelset, and $f$ is the creep coefficient. It is seen from the definition that $1 \leq p \leq 2$, and $\sigma$ and $Z$ are monotonically increasing functions of $p$. This leads to $0 \leq \delta \leq 1$; then $L_{w} \leq L \leq L_{t}$. The hunting frequency can be calculated by substituting the wavelength into the expression $v / L$, in which $L$ represents the hunting wavelength and $v$ represents the vehicle speed.

Figure 6 illustrates the hunting frequency calculated through (2)-(5) in case the equivalent conicity ranges from 0.01 to 0.5 , which corresponds to a new wheel tread and a worn tread case, respectively. In this example, $k_{p y}=8 \mathrm{MN} /$ $\mathrm{m}, k_{p \psi}=6.69 \mathrm{MN} / \mathrm{rad}, f=8 \times 10^{6} \mathrm{~N}$, and $r=0.43 \mathrm{~m}$, and the vehicle speed is $50 \mathrm{~m} / \mathrm{s}$. It is seen that the free wheelset has the highest hunting frequency, while the rigid-steering bogie experiences the lowest, and the flexible-steering bogie locates somewhere between the aforementioned cases. For the whole vehicle, its hunting frequency behaves like the flexible-steering bogie but is dependent on its steering stiffness on wheelset and the secondary suspension parameters of vehicle. Therefore, the vibration on the bogie and car body deteriorates with increasing of wheelset conicity.

3.2. Evolution of the Acceleration on $C B$. The averaged maximum acceleration on the $\mathrm{CB}$ chassis in the unfiltered and filtered cases is plotted in Figures 7 and 8, respectively. The number of recorded data sets is approximately 140 data, and each data set is classified by the running direction and stations of the tested train. The two colors of the scattered solid circles correspond to the upward-and downward-running directions on a specific high-speed railway, and other colors with other markers correspond to the result obtained when the train was operated on another line. In these two and the following plots, the upper text in the bottom $x$-axis denotes the total OD of the vehicle, and the text on the top $x$-axis denotes the OD after a wheel reprofiling. The acceleration on the $\mathrm{CB}$ remains stable with the increasing of OD except for the first 25 data sets, in which the data was recorded when the train was first put into operation, which experiences abnormal operation conditions. Additionally, it is clearly seen that the amplitude of acceleration on the $\mathrm{CB}$ in the case of downward running (blue points) is much greater than that in the case of upward running (red points) and has an approximate average of $0.5 \mathrm{~g}$ and $0.2 \mathrm{~g}$, respectively, while the vertical acceleration on the CB increases slightly with the increasing OD (approximate average of $0.2 \mathrm{~g}$ to $0.4 \mathrm{~g}$ ), and there exists no difference in the vibration amplitude between the upward-running and downward-running cases. As in Figure 8, both the lateral and vertical acceleration of the $\mathrm{CB}$ have an averaged amplitude of around $0.05 \mathrm{~g}$ and maximum value of $0.10 \mathrm{~g}$ when applying a low-pass filter (below $15 \mathrm{~Hz}$ ). Moreover, the averaged acceleration remains stable with the increasing OD. Comparing Figures 7 and 8, one can tell that it is the high-frequency component of the vibration on $\mathrm{CB}$ that rises with the increasing OD.

3.3. Vibration of CBSE Traction Transformer. The averaged maximum acceleration on the CBSE traction transformer, which has a mass of $4 \mathrm{t}$, in the unfiltered and filtered cases is plotted in Figures 9 and 10, respectively. More data sets are demonstrated in this section than that of the CB. The unfiltered lateral acceleration on the transformer has an average value of about $1.4 \mathrm{~g}$, and it is about $1.7 \mathrm{~g}$ in vertical, while the filtered acceleration has a relatively constant average of $0.10 \mathrm{~g}$ with respect to the increasing of OD.

3.4. Vibration of CBSE Traction Converter. The converter has relatively smaller acceleration than the transformer, which one can tell easily by comparing Figures 9 and 11. For the filtered vibration, as shown in Figure 12, it has averaged acceleration around $0.06 \mathrm{~g}$ in both the vertical and lateral directions. The vibration of the traction converter remains unchanged with the increasing of OD and shows no clear relation with the wheel wear and wheel reprofiling.

\section{Frequency Analysis of the CBSE Vibration}

In order to have fundamental understanding on the vibrating characteristics of the CBSE and $\mathrm{CB}$, the frequency spectrum and time-frequency spectrum are illustrated in Figure 13. In this figure, left plots depict the time signal of acceleration on the $\mathrm{CB}$ with different filter bandwidth of frequency, and the medium plots are the corresponded FFT spectrums; then the right plots illustrate the corresponding Short-Time-Fourier-Transform (STFT) spectrums. The time 


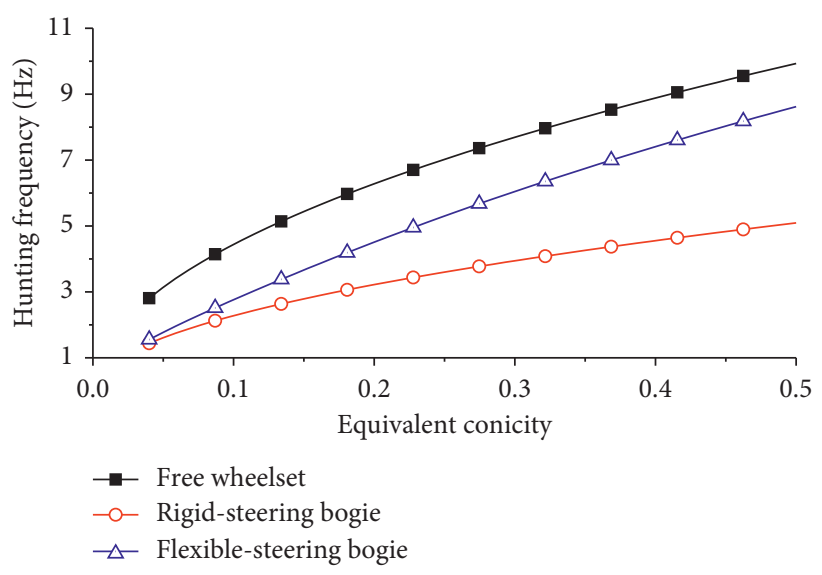

FIgURE 6: Hunting frequency of a free wheelset and rigid- and flexible-steering bogie.

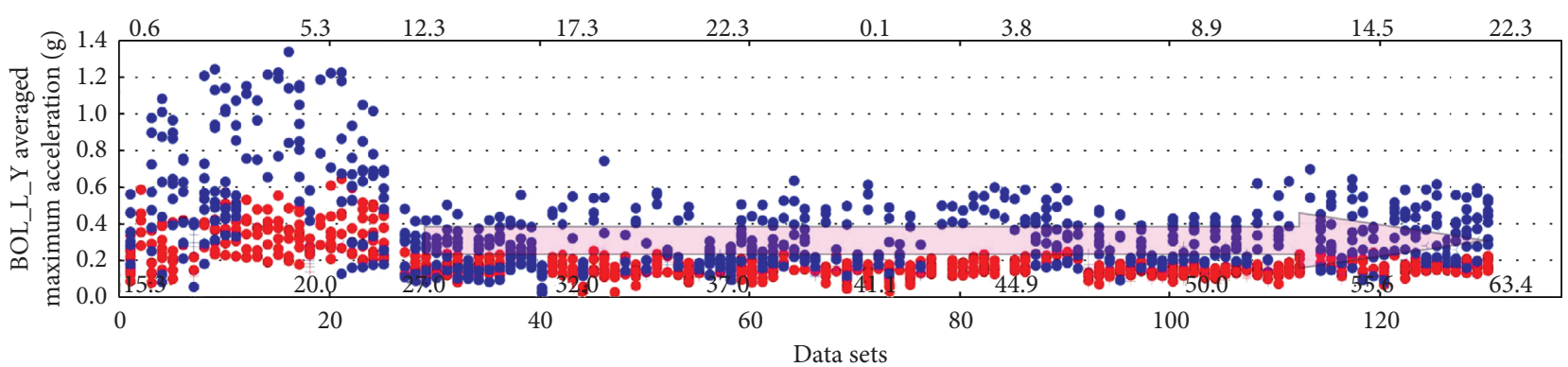

(a)

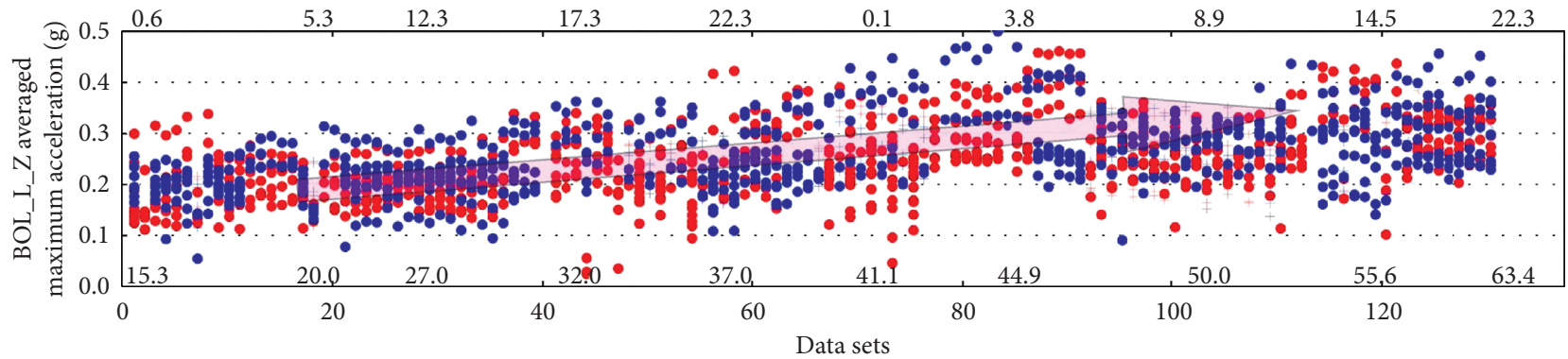

(b)

Figure 7: Evolution of the unfiltered acceleration on the CB chassis in (a) lateral and (b) vertical directions.

signals with different filter bandwidths and the corresponding FFT spectrums show that the $\mathrm{CB}$ experiences a low-frequency vibration mainly at $7 \mathrm{~Hz}$ and $13 \mathrm{~Hz}$ laterally, while the $\mathrm{CB}$ experiences high-frequency vertical vibration at $13 \mathrm{~Hz}, 75 \mathrm{~Hz}$, and $120 \mathrm{~Hz}$.

Similar to the spectrum analysis of the CB vibration, the STFT spectrum associated with the CBSE traction transformer and converter is plotted in Figures 14-16. As shown in Figures 14 and 15, the traction transformer experiences a high frequency of vibration around $100 \mathrm{~Hz}$ and its multiplications, which dominates with respect to the low-frequency vibration around $10 \mathrm{~Hz}$ vertically and $6 \mathrm{~Hz}$ laterally. One can tell that these two low-frequency vibration components correspond to the suspension frequency of the CBSE and the hunting motion of the bogie, respectively. Figure 16 shows the spectrums of the traction converter, which experiences a wide frequency bandwidth in the vertical vibration, with a much more intense component subjected to the suspension frequency around $8 \mathrm{~Hz}$. The high-frequency vibration greater than $50 \mathrm{~Hz}$ is caused by the electromagnetic excitation bears on the traction transformer and converter, while the low frequency of vibration corresponds to the suspension frequency or the excitation resulting from the bogie hunting.

\section{Coupled Vibration Analysis between the CB and CBSE}

There exists a coupling vibration between the $\mathrm{CB}$ and CBSE, in which the coupling characteristics are dependent on the bogie excitations on the $\mathrm{CB}$ and the 


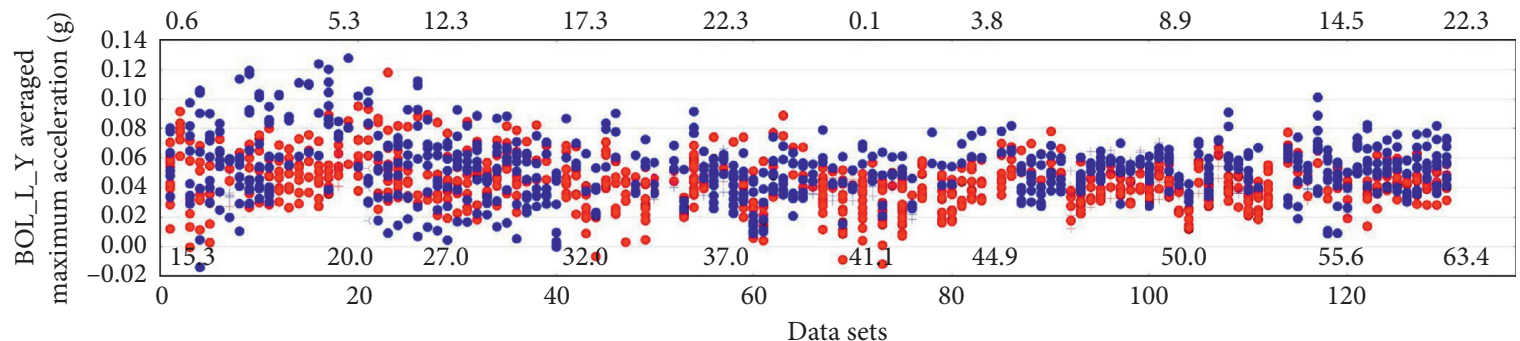

(a)

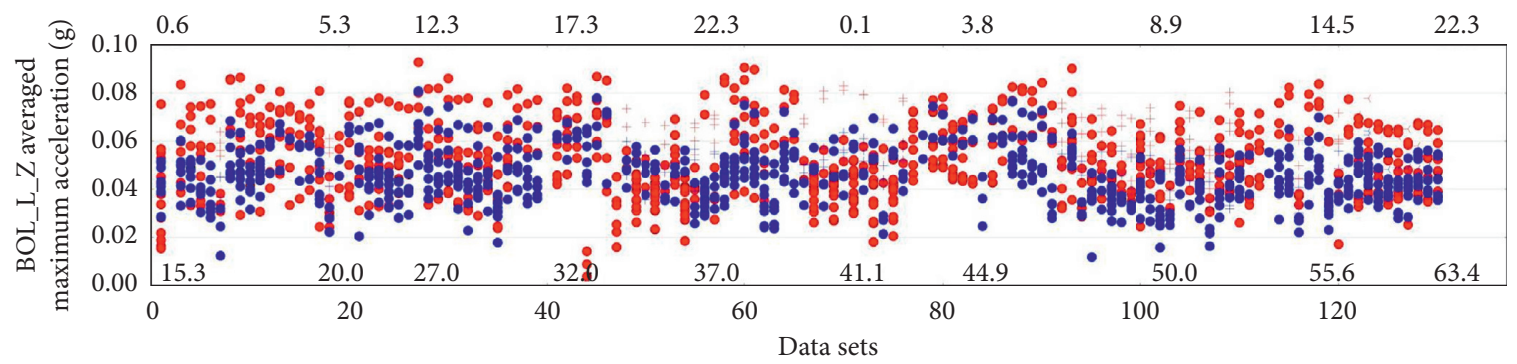

(b)

FIgURE 8: Evolution of the low-pass filtered $(15 \mathrm{~Hz})$ acceleration on the CB chassis in (a) lateral and (b) vertical directions.

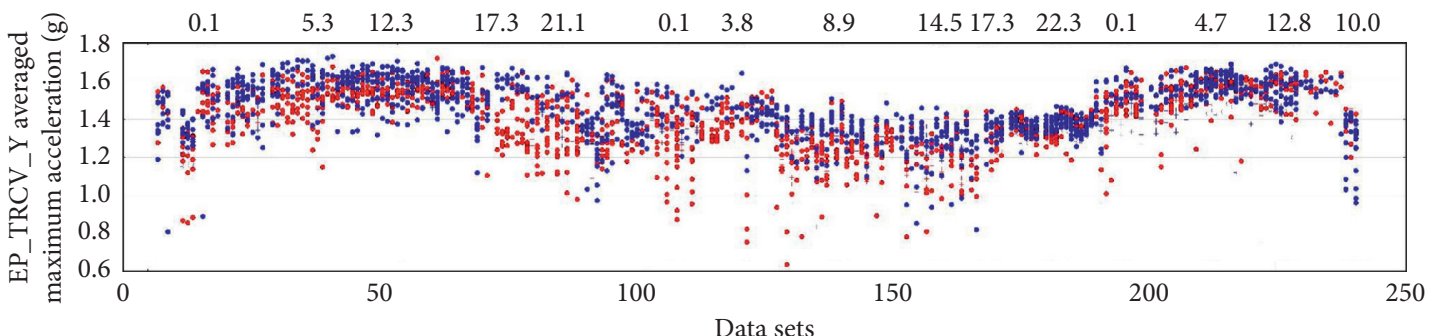

(a)

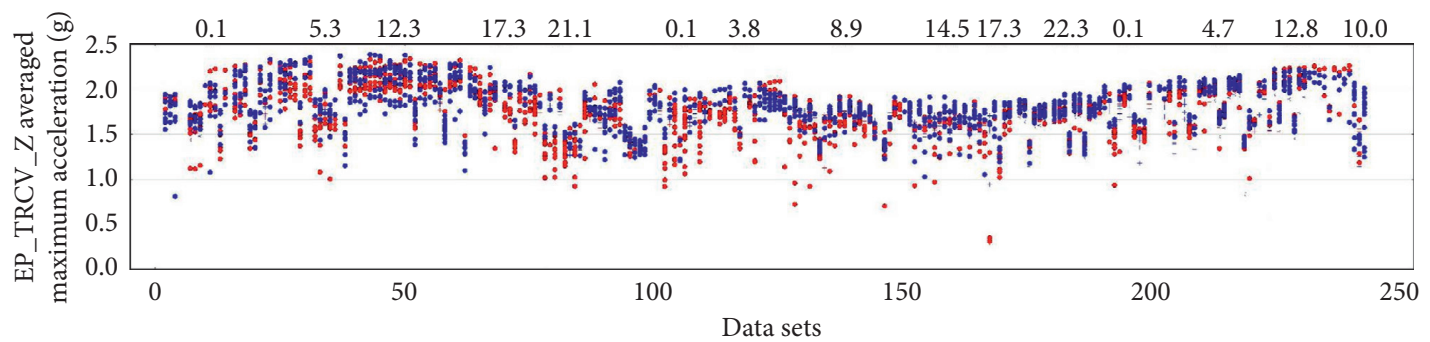

(b)

FIGURE 9: Unfiltered acceleration on CBSE traction transformer in (a) lateral and (b) vertical directions.

suspension conditions of the CBSE. Numerical analysis and lab tests have shown that a proper elastic suspension of the CBSE can be helpful in the flexible vibration reduction on the CB. Additionally, a proper parameters design in the CBSE suspension leads to isolation of the vibration from the $\mathrm{CB}$ to the CBSE. For the tested highspeed trainset $\mathrm{CRH} 380 \mathrm{~B}$, the vertical suspension frequency of the CBSE is around $8 \mathrm{~Hz}$, while it is about $6 \mathrm{~Hz}$ for the lateral suspension.
5.1. Vibration-Transmission between the $C B$ and CBSE. The lateral vibration of the bogie frame would be transmitted to the $\mathrm{CB}$ and CBSE, when the bogie surfers a hunting movement. Its hunting frequency reaches up to $8 \sim 10 \mathrm{~Hz}$ in case of an abnormal wheel-rail interaction for a worn wheel tread at a relatively high OD [3]. Figure 17 depicts the spectrums of the lateral vibration on the wheelset axle box, bogie frame, and CB. It is shown that the wheelset and bogie frame share a similar lateral vibration at the frequency of 


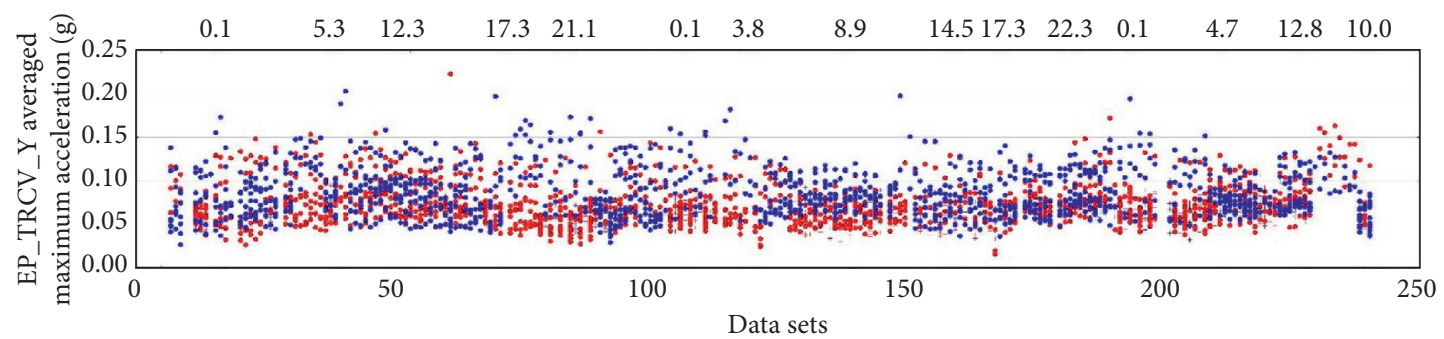

(a)

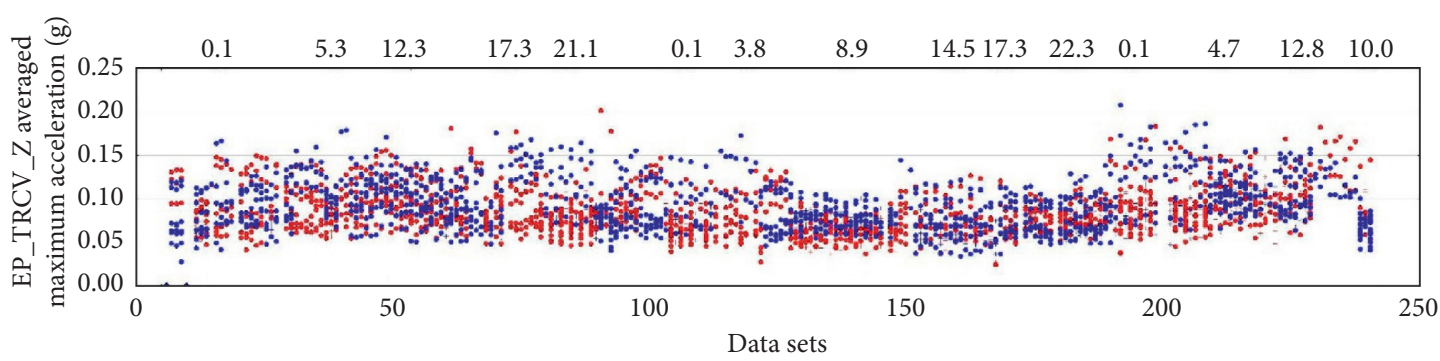

(b)

FIgURe 10: Low-pass filtered $(15 \mathrm{~Hz})$ acceleration on CBSE traction transformer in (a) lateral and (b) vertical directions.

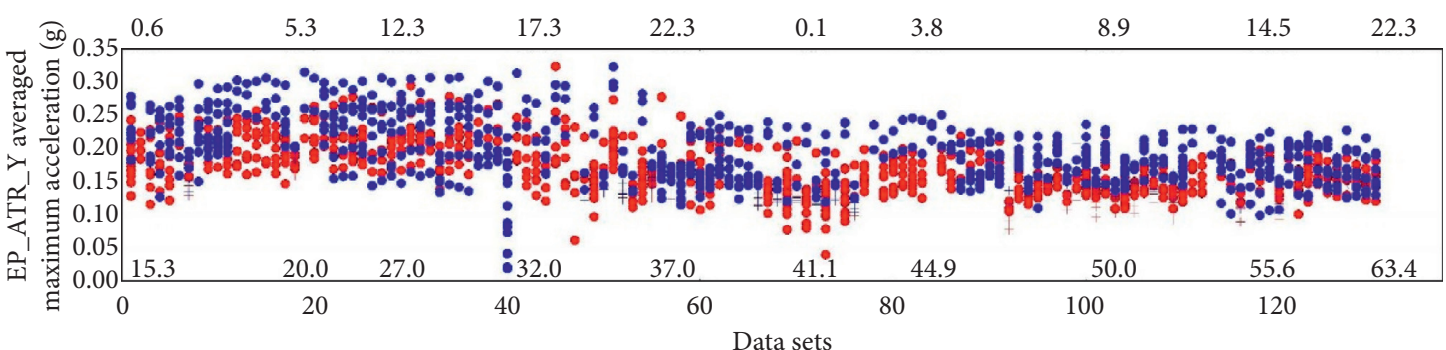

(a)

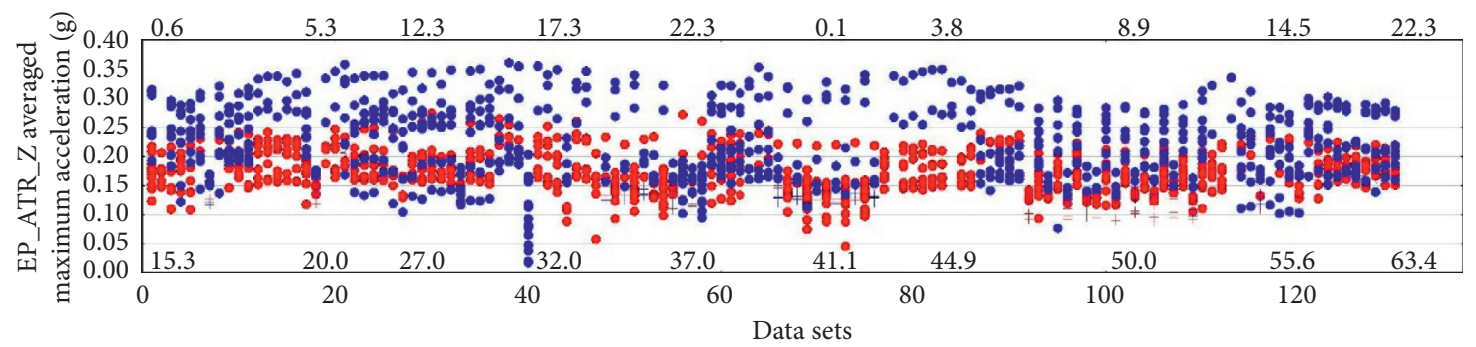

(b)

FIGURE 11: Unfiltered acceleration on CBSE traction converter in (a) lateral and (b) vertical directions.

9.2 $\mathrm{Hz}$, when the vehicle experiences a hunting motion. The $\mathrm{CB}$ experiences a harmonic vibration laterally in the same frequency with that on the bogie but less severe. One can tell that the hunting motion of the bogie has a significant effect on the $\mathrm{CB}$ vibration and ride comfort of the vehicle.

Figures 18 and 19 illustrate the lateral acceleration characteristics of the CB and CBSE traction converter at the connection point, when the bogie experiences high- and low-frequency hunting, respectively. The hunting frequencies are $9.2 \mathrm{~Hz}$ and $6.5 \mathrm{~Hz}$, respectively, and the CBSE traction converter has a lateral suspension frequency around $6 \mathrm{~Hz}$. It is found that the vibration on the CB is larger than that on the CBSE in the high-frequency hunting case (Figure 18), while it is not true in the low-frequency hunting case (Figure 19). As shown in Figure 18, the vibration on CB is isolated greatly before it is transited to the CBSE according to the vibration isolation theory that the excitation frequency $(9 \sim 11 \mathrm{~Hz})$ of the base CB is higher than that of the isolated object CBSE $(6 \mathrm{~Hz})$ by $\sqrt{2}$ times. This implies that a relatively soft suspension of the CBSE is good for isolating the vibration from the CB to the CBSE. On the contrast, the CBSE experiences severer vibration, when the bogie hunting frequency gets close to the suspension frequency of CBSE, as shown in Figure 19. DVA theory can explain this, in which 


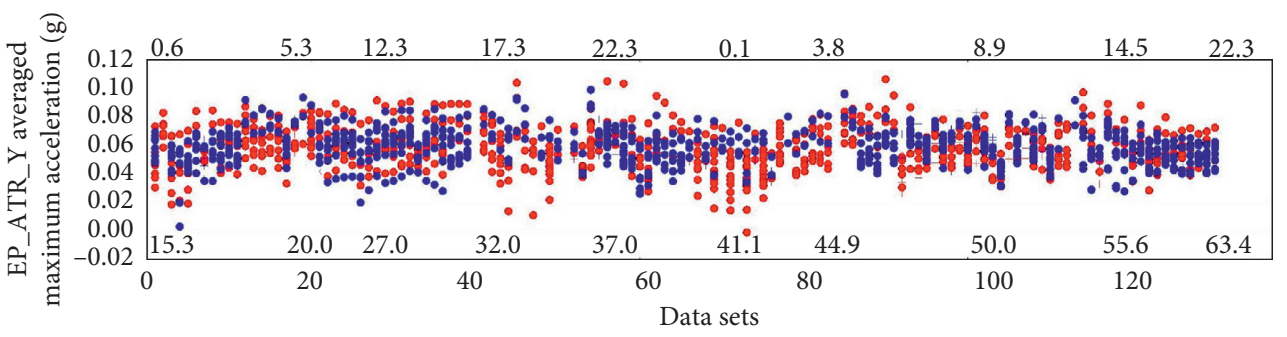

(a)

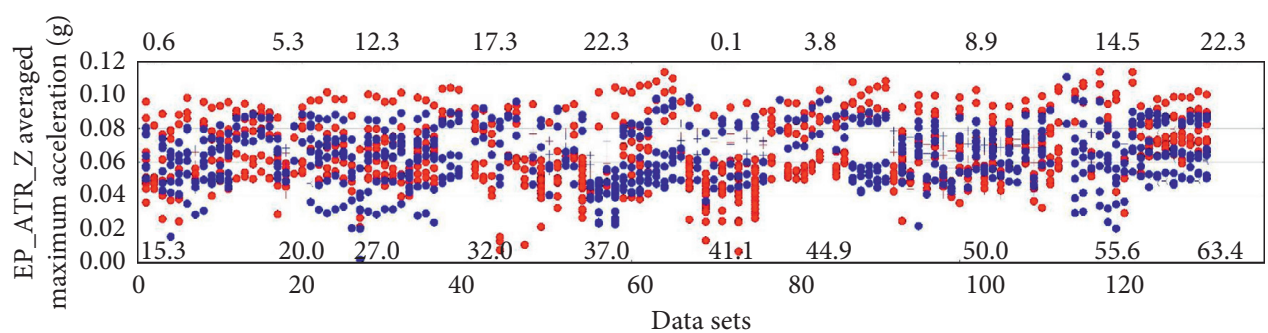

(b)

Figure 12: Low-pass filtered $(15 \mathrm{~Hz})$ acceleration on CBSE traction converter in (a) lateral and (b) vertical directions.
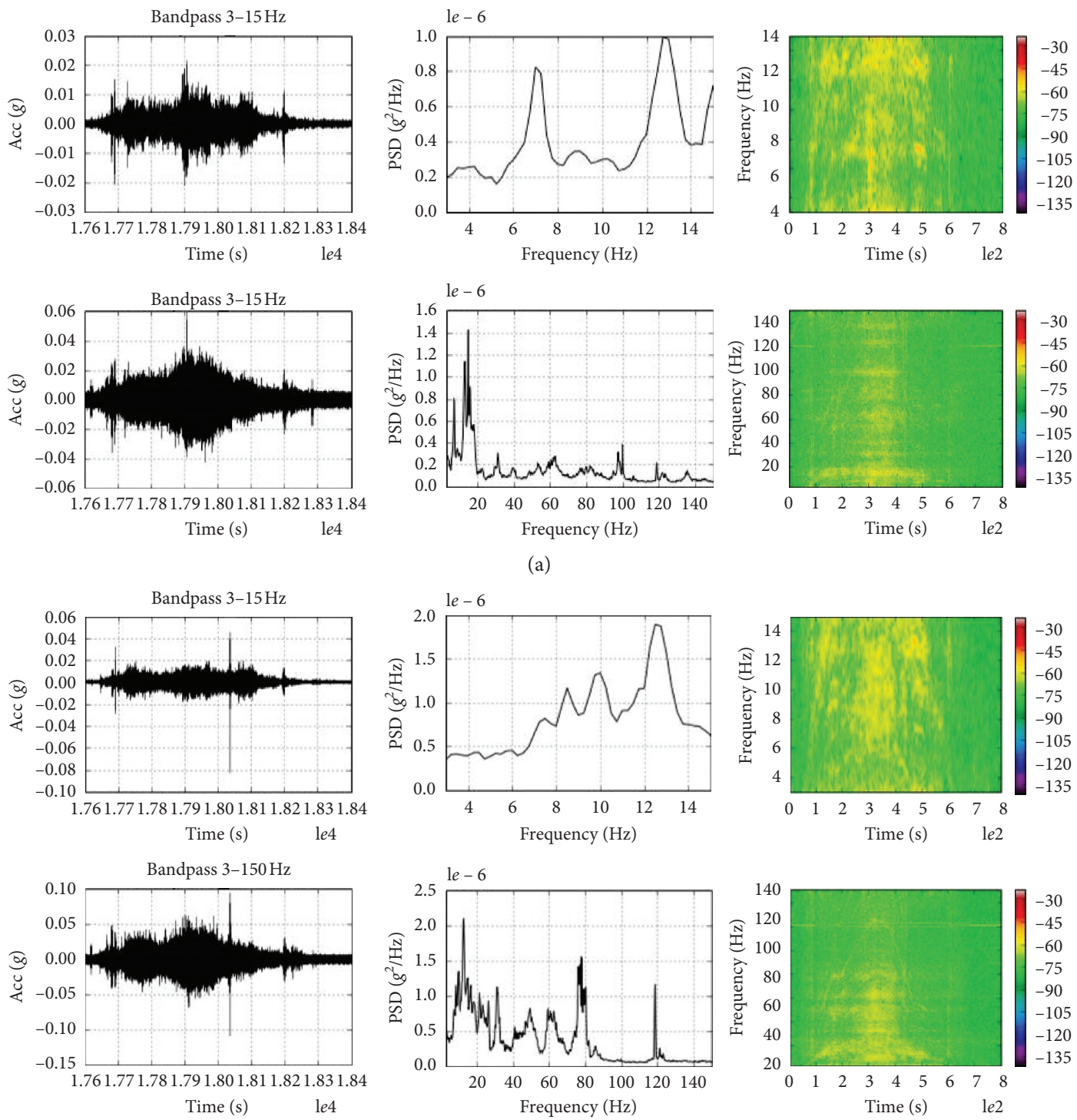

(b)

FIgURE 13: Frequency distribution of unfiltered vibration of CB: (a) lateral vibration; (b) vertical vibration. 


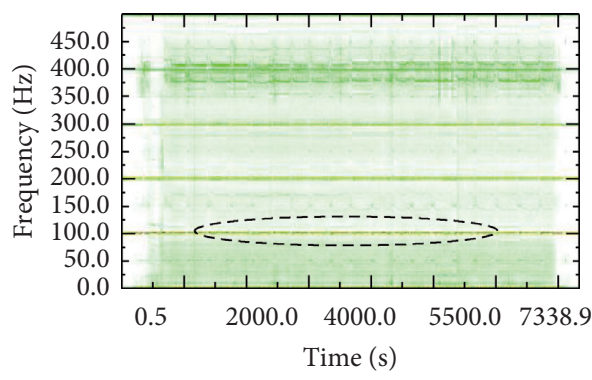

(a)

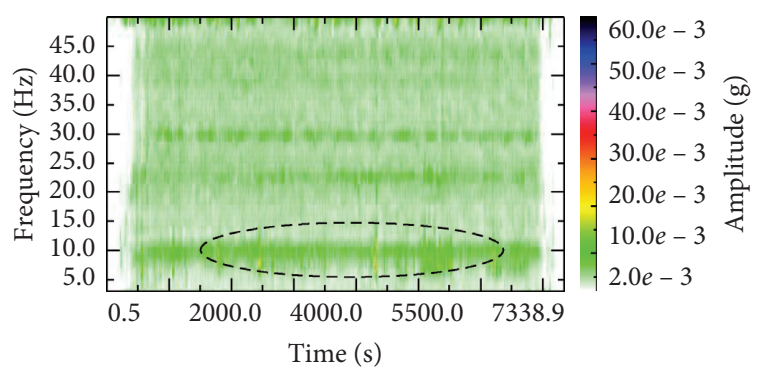

(b)

FIGURE 14: Spectrum of vertical acceleration on CBSE traction transformer: (a) zoomed; (b) enlarged.

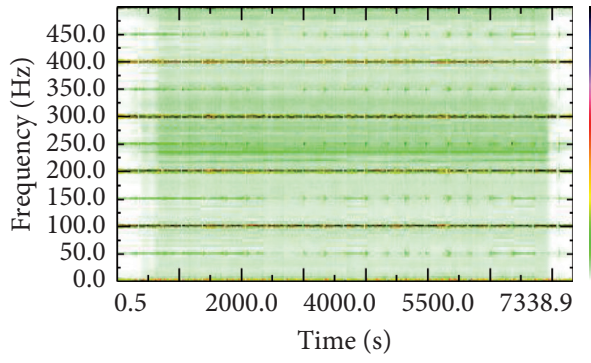

(a)

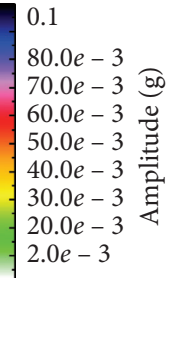

$70.0 e-3$ b

$60.0 e-3$ व

.

$30.0 e-3$

$20.0 e-3$

$0 e-3$ 


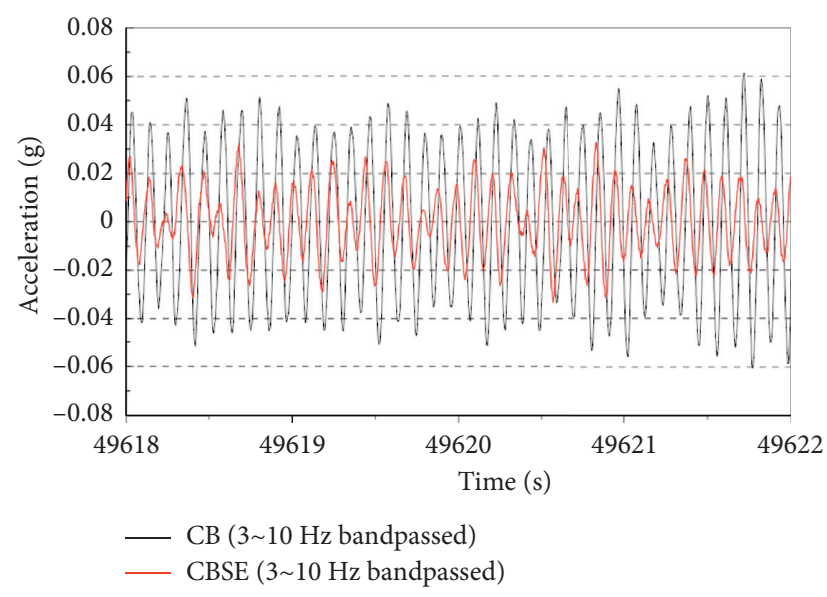

(a)

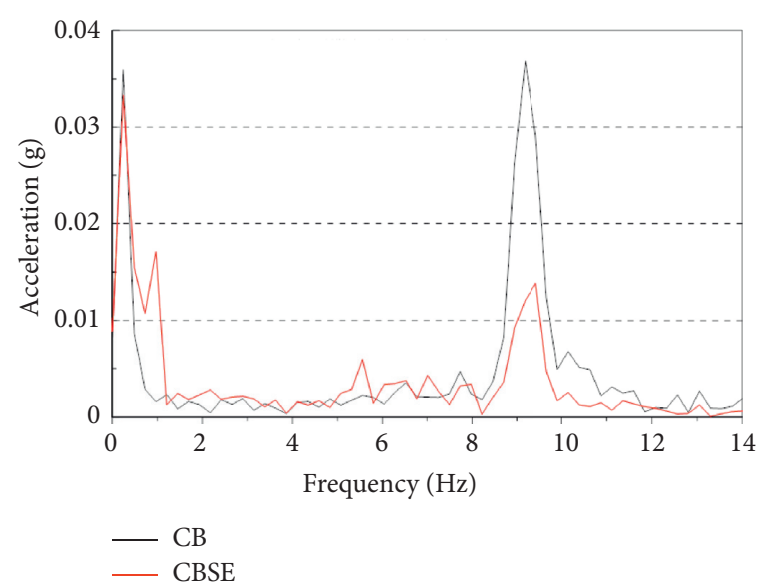

(b)

FIGURE 18: Comparisons of the lateral vibration on the CBSE and CB: (a) time history of acceleration and the corresponding; (b) spectrums when the wheel experiences little wear.

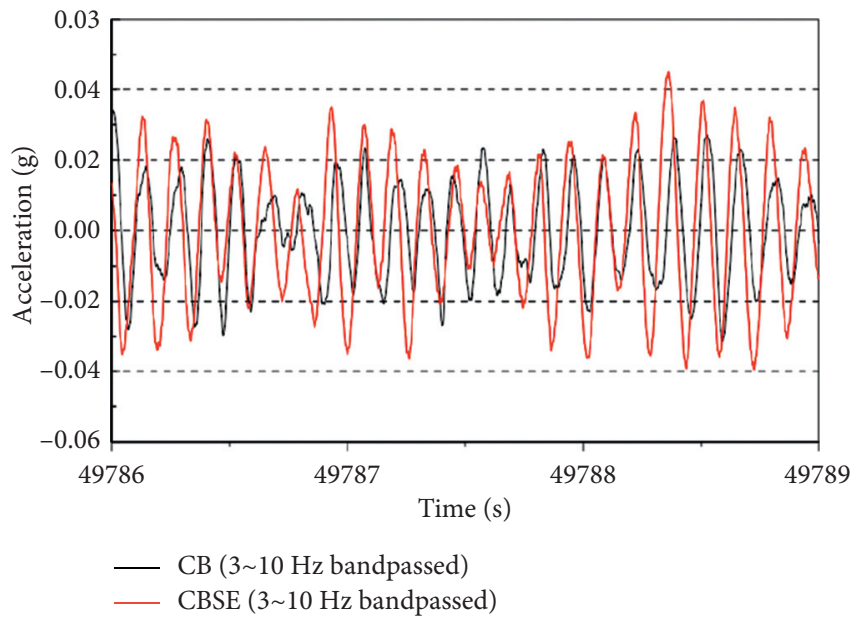

(a)

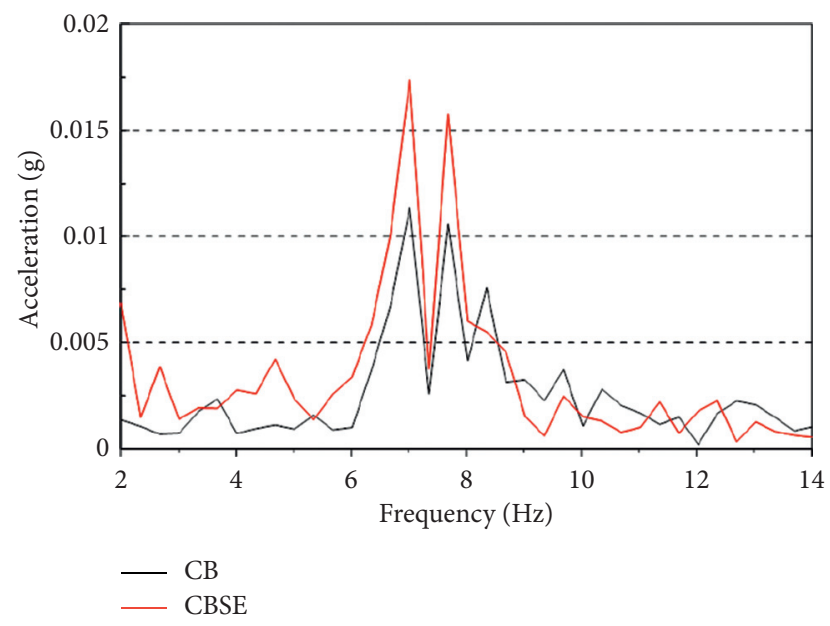

(b)

FIGURE 19: Comparisons of the lateral vibration on the CBSE and CB: (a) time history of acceleration and the corresponding; (b) spectrums when the wheel experiences severe wear.

the CBSE vibrates as a vibration absorber to absorb the vibration on the $\mathrm{CB}$ caused by the bogie hunting, since the CBSE has approximately the same frequency with that of bogie hunting. The field measurements correspond to the simulations and lab tests in works [3-6].

5.2. Excitations Subjected to the CBSE. It is well known that the high-frequency excitation on CBSE can be isolated by using elastic suspensions to avoid the excitation transmitted to the CB. The frequency of excitations that this CBSE is subjected to is usually higher than $30 \mathrm{~Hz}$. Then according to the vibration isolation theory, the suspension frequency of the CBSE shall be less than $30 / \sqrt{2}$ in order to have a smaller vibration on the $\mathrm{CB}$ than the vibration of excitation bears on the CBSE. It is $21 \mathrm{~Hz}$ in this case, and a lower suspension frequency is better for the vibration isolation. Figure 20 depicts the spectrums of the vertical acceleration on CBSE with various OD cases considered. It is shown that the amplitude of the dominant frequency on $\mathrm{CB}$ vertical vibration within $150 \mathrm{~Hz}$ is less than $0.01 \mathrm{~g}$, while it reaches up to $0.1 \mathrm{~g}$ for the CBSE. This shows that the high-frequency vibration transmitted from the CBSE is reduced by a level in the amplitude to the $\mathrm{CB}$. Additionally, the amplitude of these spikes in the spectrum increases greatly with the increasing of $\mathrm{OD}$ due to the deterioration of vehicle dynamics and aging of the rubber element in the CBSE suspension.

Table 2 summarises the vibration characteristics of commonly used CBSE on the high-speed train, in which they are characterized by the suspension frequency and excitations they are subjected to. The traction transformer and converter have the largest mass among the CBSE. They have a mass greater than $2 \mathrm{t}$ which reaches up to $6 \mathrm{t}$ and are 

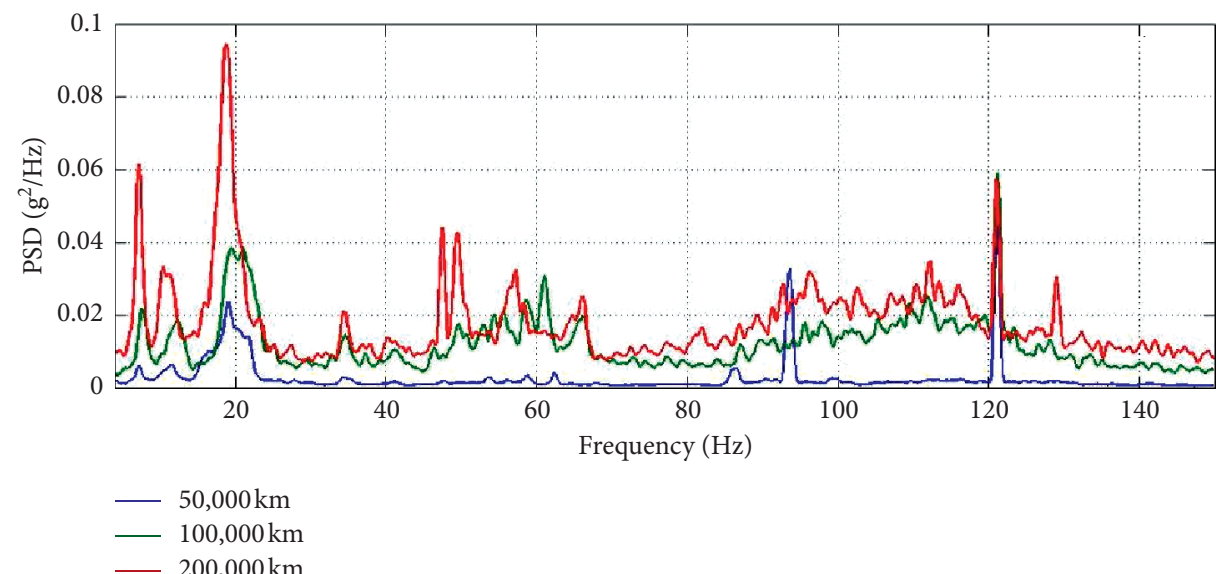

(a)

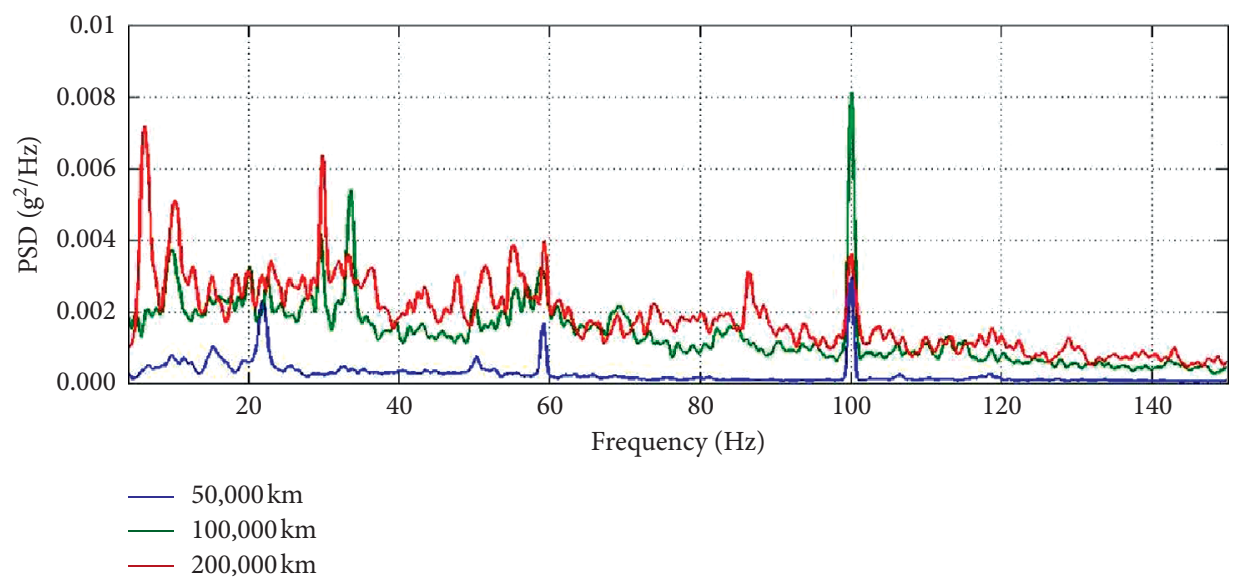

(b)

FIGURE 20: Spectrums of the vertical acceleration on the (a) CBSE traction converter and (b) CB.

TABLE 2: Frequency characteristics of the CBSE.

\begin{tabular}{lcc}
\hline Name & Suspension & Excitation \\
\hline $\begin{array}{l}\text { Traction } \\
\text { transformer }\end{array}$ & Approximately $8 \mathrm{~Hz}$ and $6 \mathrm{~Hz}$ for the vertical and lateral suspension, & 50 or $60 \mathrm{~Hz}$ and $100 \mathrm{~Hz}$ and their \\
respectively & multiplications \\
$\begin{array}{l}\text { Traction converter } \\
\text { Braking unit }\end{array}$ & $\begin{array}{c}\text { Approximately } 8 \mathrm{~Hz} \text { and } 5 \sim 6 \mathrm{~Hz} \text { for the vertical and lateral suspension, } \\
\text { respectively }\end{array}$ & $\begin{array}{c}100 \mathrm{~Hz} \text { and its multiplications } \\
\text { Waste storage }\end{array}$ \\
\hline
\end{tabular}

generally suspended at a frequency of $6 \sim 8 \mathrm{~Hz}$ for the excitation (electromagnet vibration) isolation. For the light equipment which has a mass less than $2 \mathrm{t}$, they are usually stiffly connected to the CB by a high stiff suspension. As for some CBSE that are subjected to the rotational unbalance in mass and the mechanical impact, they use very soft suspension to isolate the excitation from the $\mathrm{CB}$.

\section{Conclusions}

In order to grasp the vibrating characteristics on the car body and the car body-suspended equipment and their evolution with the wheel wear, a long-term measurement for the high- speed train was performed on track. The test configuration was firstly organized and followed by the data analysis in the time and frequency domains with the increasing of OD to about a total of $2,400,000 \mathrm{~km}$.

(1) The conicity of the wheelset increases about 0.008 per $10,000 \mathrm{~km}$ of OD, which increases approximately linearly with the increasing of OD from 0.10 to 0.40 and the two types of wheel treads, S1002CN and LMB10, have different ranges of conicity and reprofiling cycles in OD. The theoretical analysis shows that the vibrating frequency on the bogie rises with the wheelset equivalent conicity resulting from wheel wear and then deteriorates the vehicle vibration amplitude. 
(2) The lateral acceleration on $\mathrm{CB}$ in the case of downward running is much greater than that in the case of upward running and has an approximate average of $0.5 \mathrm{~g}$ and $0.2 \mathrm{~g}$, respectively, while the vertical acceleration on the $\mathrm{CB}$ increases slightly with the increasing of the OD (approximate average of $0.2 \mathrm{~g}$ to $0.4 \mathrm{~g}$ ), and there exists no notable difference between the upward-running and downward-running cases, whereas the low-pass filtered acceleration below $15 \mathrm{~Hz}$ indicates that the averaged acceleration remains stable with the increasing of $\mathrm{OD}$, and both the lateral and vertical vibration on the $\mathrm{CB}$ have an averaged amplitude of around $0.05 \mathrm{~g}$ and maximum value of $0.10 \mathrm{~g}$.

(3) The unfiltered lateral acceleration on the transformer has an average value of about $1.4 \mathrm{~g}$, and it is about $1.7 \mathrm{~g}$ in the vertical acceleration, while the filtered acceleration has a relatively constant average of $0.10 \mathrm{~g}$ with the increasing of OD. In addition, the vibration on the CBSE remains stable regarding the running direction and $\mathrm{OD}$ of vehicle.

(4) The $\mathrm{CB}$ experiences a low-frequency vibration mainly at $7 \mathrm{~Hz}$ and $13 \mathrm{~Hz}$ laterally, while the vertical vibration on $\mathrm{CB}$ experiences a high-frequency vibration at $13 \mathrm{~Hz}, 75 \mathrm{~Hz}$, and $120 \mathrm{~Hz}$, and the traction transformer experiences a high frequency of vibration around $100 \mathrm{~Hz}$ and its multiplications, which dominates with respect to the low-frequency vibration around $10 \mathrm{~Hz}$ vertically and $6 \mathrm{~Hz}$ laterally.

(5) The CB has harmonic vibrating forms laterally in the same frequency with that on the bogie but less severe. It is concluded that the hunting motion of bogie has significant effects on the $\mathrm{CB}$ vibration and ride comfort of the vehicle.

(6) A low suspension frequency of CBSE helps the highfrequency vibration be isolated to the $\mathrm{CB}$. The amplitude of the dominant frequency on $\mathrm{CB}$ vertical vibration is less than $0.01 \mathrm{~g}$, while it reaches up to $0.1 \mathrm{~g}$ on the CBSE, which implies that the highfrequency vibration on the CBSE can be reduced by a level owed to a soft suspension. Regarding the design principle of the CBSE suspension, the vibration isolation theory and DVA theory should be employed. For further vibration reduction on both $\mathrm{CB}$ and CBSE, active suspensions may be involved.

\section{Data Availability}

The data used to support the findings of this study have not been made available because the data that have been used are confidential and owned by CRRC Changchun Railway Vehicles Co., Ltd. The authors are funded to perform the field tests and allowed to use the data for scientific research only. Thus, the authors do not have permission to share the data.

\section{Conflicts of Interest}

The authors declare that they have no conflicts of interest.

\section{Acknowledgments}

This work was supported by the projects of National Natural Science Foundation of China (nos. 51805451 and 11790282), Independent R\&D Project of State Key Laboratory of Traction Power (no. 2018TPL_T08), and Fundamental Research Funds for the Central Universities (no. 2682019CX43).

\section{References}

[1] L. Wei, J. Zeng, and J. Wang, "Carbody elastic vibrations of high-speed vehicles caused by bogie hunting instability," Vehicle System Dynamics, vol. 55, no. 9, pp. 1321-1342, 2017.

[2] H. Shi and P. Wu, "Flexible vibration analysis for car body of high-speed EMU," Journal of Mechanical Science and Technology, vol. 30, no. 1, pp. 55-66, 2016.

[3] M. Dumitriu, "On the critical points of vertical vibration in a railway vehicle," Archive of Mechanical Engineering, vol. 61, no. 4, pp. 609-625, 2014.

[4] M. Dumitriu, "Influence of suspended equipment on the carbody vertical vibration behaviour of high-speed railway vehicles," Archive of Mechanical Engineering, vol. 63, no. 1, pp. 145-162, 2016

[5] H. Shi, R. Luo, P. Wu et al., "Application of DVA theory in vibration reduction of carbody with suspended equipment for high-speed EMU," Science China Technological Sciences, vol. 57, no. 7, pp. 1425-1438, 2014.

[6] H. Wu, P. Wu, J. Zeng et al., "Influence of equipment under car on car body vibration," Journal of Traffic and Transportation Engineering, vol. 12, no. 5, pp. 50-56, 2012.

[7] G. Luo, J. Zeng, and Q. Wang, "Identifying the relationship between suspension parameters of underframe equipment and carbody modal frequency," Journal of Modern Transportation, vol. 22, no. 4, pp. 206-213, 2014.

[8] D. Gong, J. Zhou, W. Sun et al., "Method of multi-mode vibration control for the carbody of high-speed electric multiple unit trains," Journal of Sound and Vibration, vol. 409, pp. 94-111, 2017.

[9] Q. Wang, J. Zeng, G. Luo et al., "Study on vibration behavior of carbody underneath suspended systems under wheel profile wear," Journal of Mechanical Engineering, vol. 52, no. 10, pp. 113-118, 2016.

[10] H. Shi, J. Wang, P. Wu et al., "Field measurements of the evolution of wheel wear and vehicle dynamics for high-speed trains," Vehicle System Dynamics, vol. 56, no. 8, pp. 11871206, 2017.

[11] E. Andersson, N. G. Nilstam, and L. Ohlsson, "Lateral track forces at high speed curving comparisons of practical and theoretical results of Swedish high speed train $\times 2000$," Vehicle System Dynamics, vol. 25, no. S1, pp. 37-52, 1996.

[12] L. Gasparetto, S. Alfi, and S. Bruni, "Data-driven conditionbased monitoring of high-speed railway bogies," International Journal of Rail Transportation, vol. 1, no. 1-2, pp. 42-56, 2013.

[13] F. Gan, H. Dai, H. Gao et al., "Wheel-rail wear progression of high speed train with type S1002CN wheel treads," Wear, vol. 328-329, pp. 569-581, 2015.

[14] J. Wang, C. Song, P. Wu et al., "Wheel reprofiling interval optimization based on dynamic behavior evolution for high speed trains," Wear, vol. 366-367, pp. 316-324, 2016.

[15] J. Guo, H. Shi, R. Luo et al., "Parametric analysis of the car body suspended equipment for railway vehicles vibration reduction," IEEE Access, vol. 7, pp. 88116-88125, 2019. 
[16] UIC Code 518, Testing and Approval of Railway Vehicles from the Point of View of Their Dynamic Behaviour-Safety-Track Fatigue-Running Behaviour, International Union of Railways, Paris, France, 4th edition, 2009.

[17] BS EN 14363, Railway Applications-Testing and Simulation for the Acceptance of Running Characteristics of Railway Vehicles-Testing of Running Behaviour and Stationary Tests, CEN, Brussels, Belgium, 2nd edition, 2016.

[18] UIC Code 519, Method for Determining the Equivalent Conicity, International Union of Railways, Paris, France, 1st edition, 2004.

[19] W. Zhai, P. Liu, J. Lin et al., "Experimental investigation on vibration behaviour of a CRH train at speed of $350 \mathrm{~km} / \mathrm{h}$," International Journal of Rail Transportation, vol. 3, no. 1, pp. 1-16, 2015.

[20] G. Li, X. Li, C. Song et al., "Influence of service environment on the wheel wear of high speed trains," in Proceedings of the 11th International Conference on Contact Mechanics and Wear of Rail/Wheel Systems, pp. 536-542, Netherlands, Amsterdam, September 2018.

[21] R. Luo and H. Shi, Dynamics of Railway Vehicle Systems and Application, Southwest Jiaotong University Publishers, Chengdu, China, 2018. 